\title{
NEWS
}

\section{Bookshelf: A Selection of Recent Publications from the UCL Institute of Archaeology}

\author{
Jennifer French and Marion Cutting
}

The Institute of Archaeology produces two well-established series of books with Routledge: a General Series (series editor Ruth Whitehouse) and the Critical Cultural Heritage sub-series (series editor Beverley Butler).

In addition, the Institute has recently launched a new partnership with BAR Publishing to publish largely unaltered PhD theses. This substantial series is already proving popular and will promote the Institute's outstanding postgraduate research programme across the theory and practice of archaeology, conservation and heritage.

One book in the Critical Cultural Heritage Series has been published since January 2019, with one manuscript in production and two in revision following refereeing for the General Series. A further seven manuscripts are in preparation for refereeing. The first book in the BAR UCL Institute of Archaeology PhD Series has been published, with a further two volumes accepted for imminent publication.

\section{Routledge Series}

\section{Colin Sterling. 2019. Heritage,} Photography, and the Affective Past This book examines the production, consumption and interpretation of photography

UCL Institute of Archaeology, London WC1H OPY, GB Corresponding author: Jennifer French (jennifer.french@ucl.ac.uk)

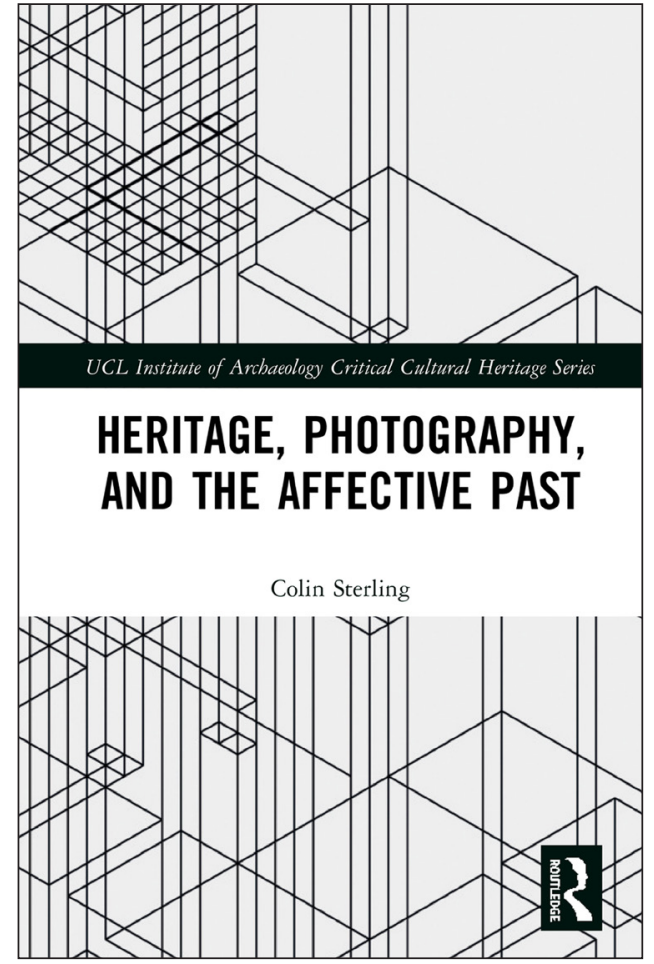

across various heritage domains, from global image archives to the domestic arena of the family album. Through original ethnographic and archival research, it sheds new light on the role photography has played in the emergence, expansion and articulation of heritage in diverse sociocultural contexts. This book provides fresh insight as to the making and remaking of the past in the present, and the alternative heritages that 
might come into being around emergent photographic forms and approaches. It uses photography as a method of enquiry as well as a tool of documentation.

\section{BAR UCL Institute of Archaeology PhD Series}

\section{Hana Lewis. 2019. Pattern and Process in the Material Culture of Anglo-Saxon Non-elite Rural Settlements}

The research presented in this book advances scholarship on Anglo-Saxon non-elite rural settlements through the analysis of material culture. Forty-four non-elite sites and the high-status site of Staunch Meadow, occupied throughout the Anglo-Saxon period (c. $5^{\text {th }}-11^{\text {th }}$ centuries) and geographically representative of Anglo-Saxon settlement in England, were selected for study. Comparative analyses of the material culture assemblages and settlement data from these sites were evaluated from four main research perspectives: the archaeological contexts and distributional patterns of material culture at the sites; the range and character of material culture; patterns of material culture consumption; and material culture as evidence for the economic reach of rural settlements.

Many other books have been published by Institute staff between 2018 and 2019. Some of these are featured below.

\section{Giles Dawkes. 2019. Living by the Creek: Excavations at Kemsley, Sittingbourne, Kent. Archaeology South-East/SpoilHeap Publications Occasional Paper 10}

A series of archaeological investigations carried out along the route of the Sittingbourne Northern Relief Road identified a multi-period site dating from the earlier prehistoric to the Roman periods. Most significant was a Roman salt-evaporation hearth or saltern identified on the edge of the marsh, as few have been subject to modern excavation and are a rare find in the region, despite the known importance of the Roman salt-production industry in the Thames estuary.
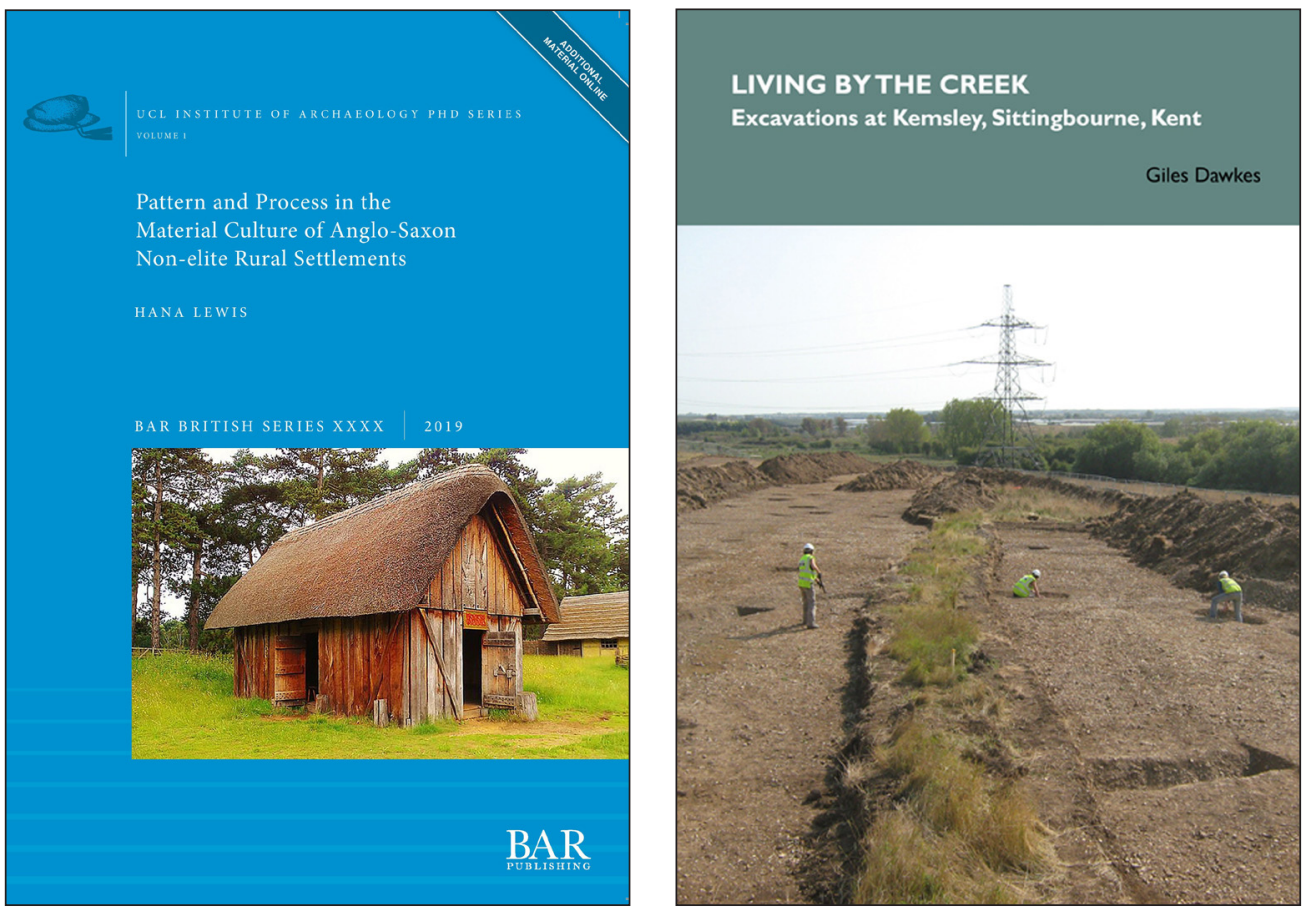
Julio Escalona, Orri Vésteinsson and Stuart Brookes (Eds). 2019. Polity and Neighbourhood in Early Medieval Europe. Turnhout: Brepols Publishers, Medieval Countryside Book 21

How were early medieval people connected to each other and to the wider world? In this collection, archaeologists and historians working in very different areas of early medieval Europe explore diverse evidence-from landscape and burial archaeology to charters and chronicles-to discuss the relationships that constituted neighbourhoods and the roles these played in the processes of state formation that can be observed in the peripheries of the Frankish world.

\section{Emma Lightfoot, Xinyi Liu and Dorian Q Fuller (Eds). 2018. Far from the Hearth: Essays in Honour of Martin K. Jones. Cambridge: McDonald Institute for Archaeology Research Monographs}

A collection of essays on the archaeology of food and agriculture, including

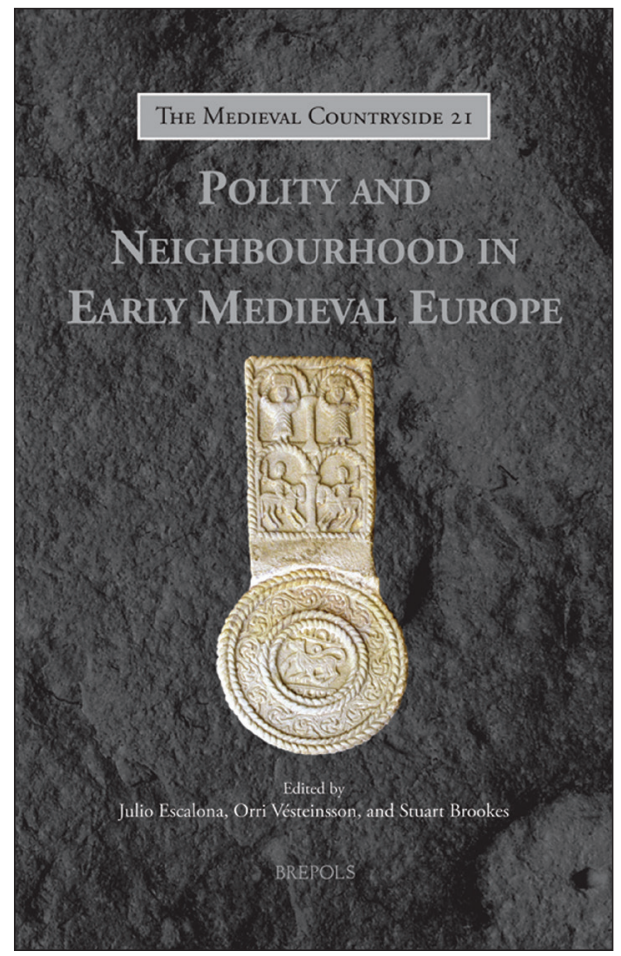

discussions of the origins of agriculture, agricultural ecology, archaeobotanical methods, biomolecular archaeology and agricultural genetics, food and agricultural systems as states of mind, and the globalization of crops across Eurasia in the later Holocene.

\section{Gabriel Moshenska. 2019. Material} Cultures of Childhood in Second World War Britain. London:

Routledge, Material Culture and Modern Conflict Series

This book draws on memory narratives to construct an historical anthropology of childhood in Second World Britain, focusing on objects and spaces such as gas masks, air raid shelters and bombed-out buildings. In their struggles to cope with the fears and upheavals of wartime, with families divided and familiar landscapes lost or transformed, children reimagined and reshaped these material traces of conflict into toys, treasures and play grounds.

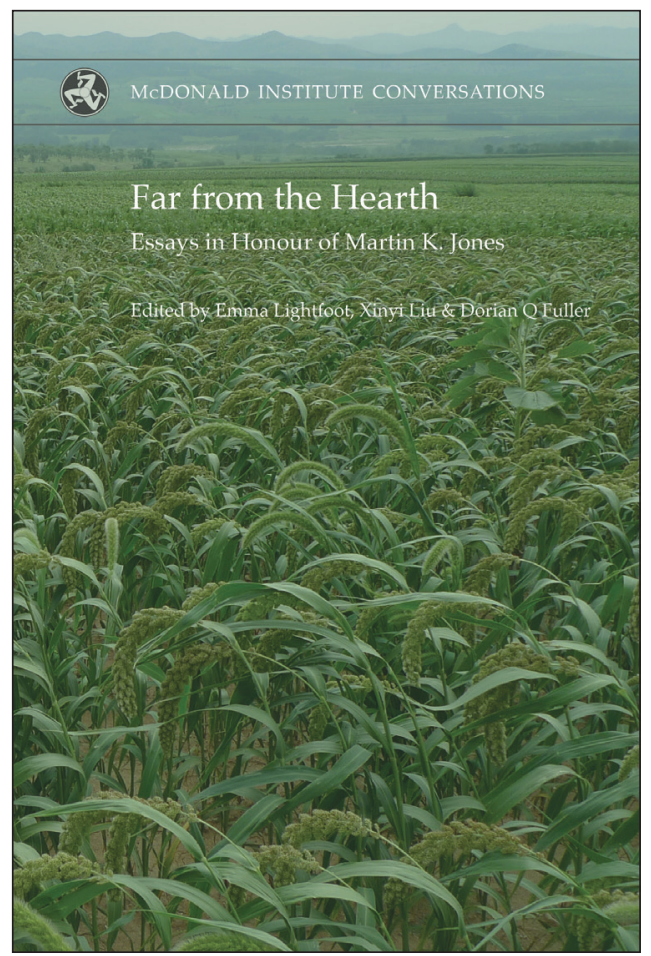




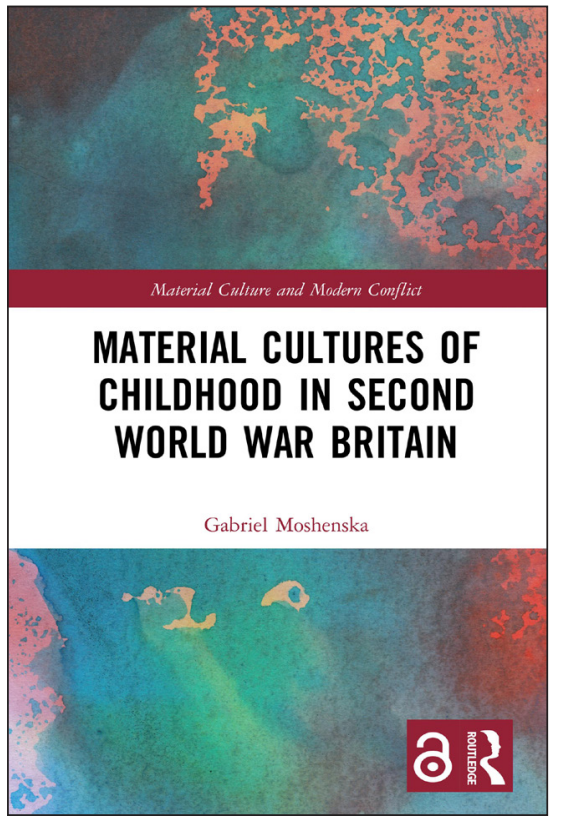

Giorgos Papantoniou, Demetrios Michaelides and Maria DikomitouEliadou (Eds). 2019. Hellenistic and Roman Terracottas. Leiden: Brill, Monumenta Graeca et Romana Vol. 23 A collection of 29 chapters presenting diverse and innovative approaches in the study of ancient terracottas across the Mediterranean and the Near East, from the Hellenistic period to Late Antiquity. The authors advocate a holistic approach to the study of coroplastic art, which considers terracottas not simply as works of art but also as integral components of ancient material culture. An invaluable companion to ancient terracottas and their associated iconography and technology, as well as in ancient artefacts and classical archaeology in general.

Mike Parker Pearson, Alison

Sheridan, Mandy Jay, Andrew Chamberlain, Mike Richards and Jane Evans (Eds). 2019. The Beaker People: Isotopes, Mobility and Diet in Prehistoric Britain. Oxford: Oxbow Books, Prehistoric Society Research Paper 7

This volume addresses century-old questions about the people who were buried
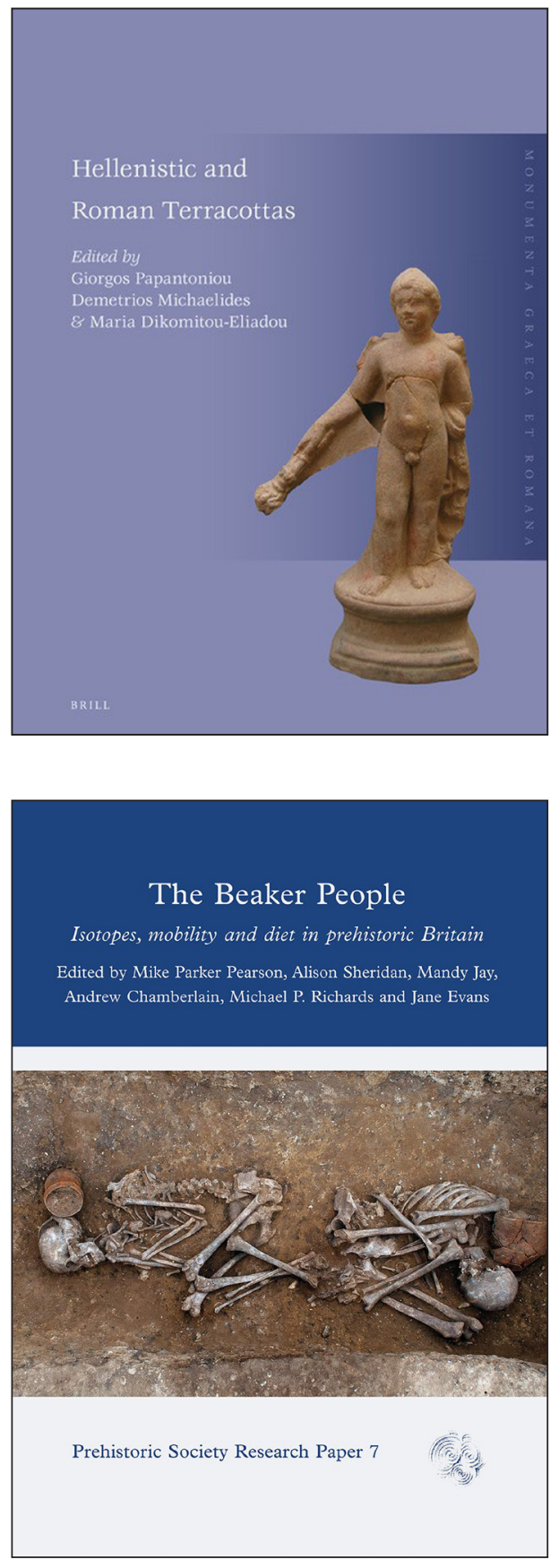

with Beakers - the distinctive pottery of Continental origin that was current, predominantly in equally distinctive burials, in Britain from around $2450 \mathrm{BC}$. Around 300 skeletons were subjected to isotope analysis to explore patterns of mobility and diet, and 150 new radiocarbon dates were 
obtained. Dental microwear was examined for 64 individuals to provide further information about the food they had eaten, and new information on the sex and age of 201 people obtained. While the genetic data provide convincing evidence for immigration by Continental Beaker users, the isotopic data indicate a more detailed picture of movements, mostly of fairly short distances within Britain, by the descendants of the first Beaker users.

Michael Shapland. 2019. Anglo-Saxon Towers of Lordship. Oxford: Oxford University Press

Anglo-Saxon lords constructed free-standing towers at their residences all across England over the course of the tenth and eleventh centuries. This is the first fulllength study of these exceptional buildings, which appear to have had a dual function as buildings of elite worship and symbols of secular power and authority. They persisted into early Norman England, where they appear to have influenced a variety of high-status building types, including the

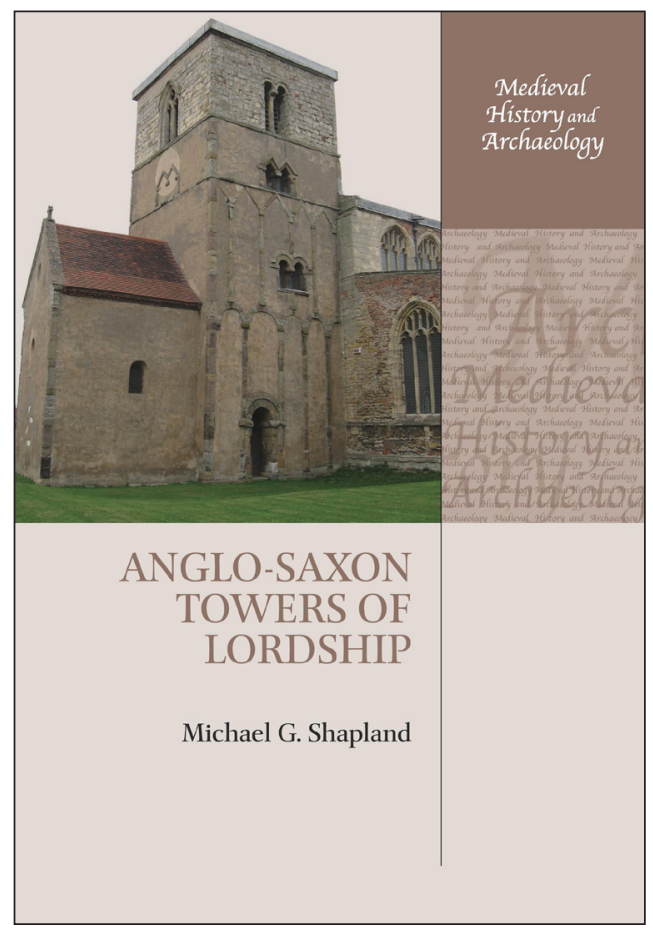

keeps and gatehouses of the earliest stone castles.

\section{Pip Stephenson and Kristina}

Krawiec. 2019. A View From The Edge: Archaeological Investigation on the Manhood Peninsula, Selsey for the Medmerry Managed Realignment Scheme. Archaeology South-East/SpoilHeap Publications Monograph 20

Between 2010-2013, the Environment Agency undertook the managed realignment of the coastline at Medmerry, impacting on upwards of 60ha of landscape with rich archaeological potential. The opportunity for research offered by the scheme provided a window into the evolution of this distinctive coastal landscape from the earliest period of human settlement in the Bronze Age through to the modern era. The geoarchaeological and palaeoenvironmental programme produced a significant sediment archive, an important contribution to the study of the Manhood Peninsula.

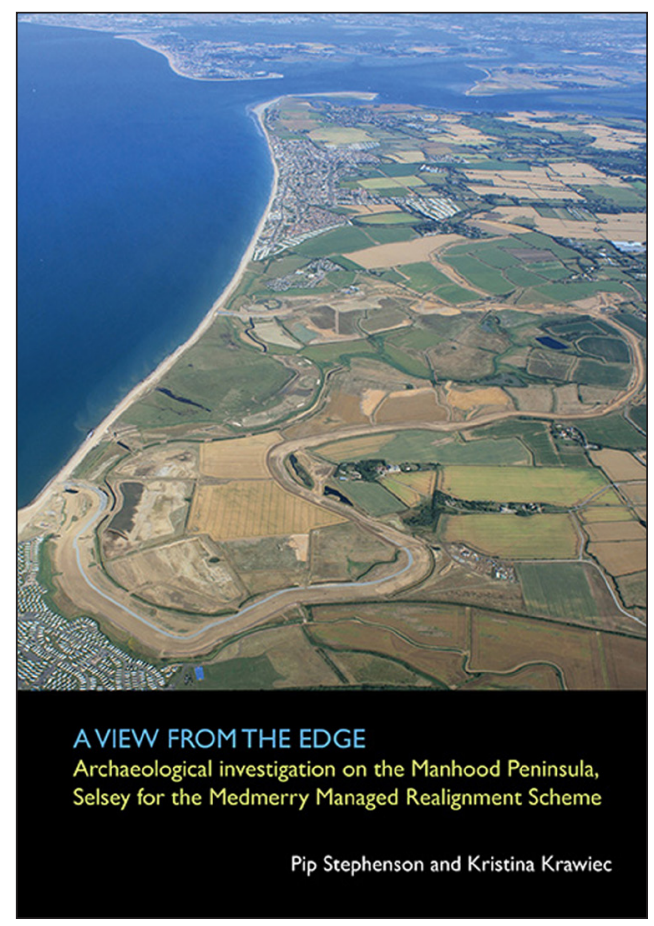


Alice Stevenson. 2019. Scattered Finds: Archaeology, Egyptology and Museums. London: UCL Press

Scattered Finds explores the politics, personalities and social histories that linked fieldwork in Egypt with the varied organizations around the world that received Egyptian finds. By juxtaposing a diversity of sites for the reception of Egyptian cultural heritage over the period of a century, the book presents new ideas about the development of archaeology, museums and the construction of Egyptian heritage. It further addresses the legacy of these practices and argues for a stronger ethical commitment to its stewardship.

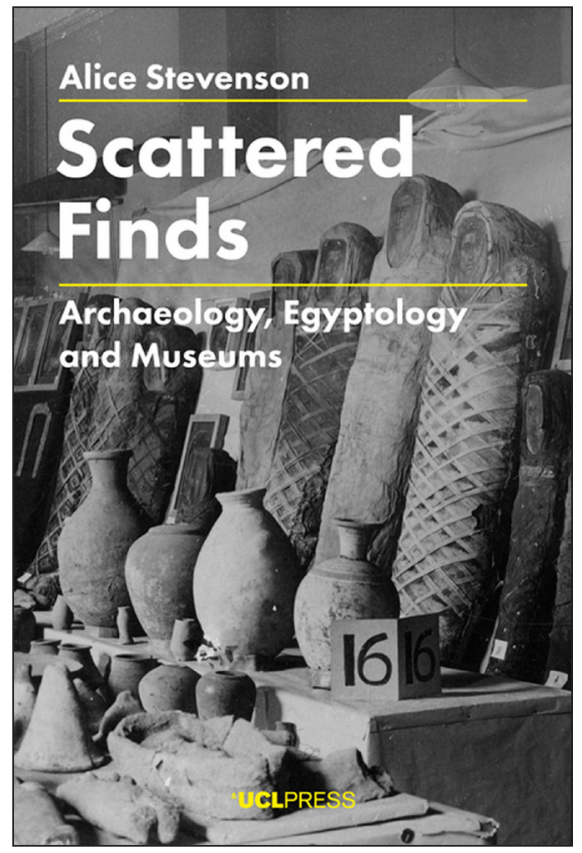

Naomi Sykes and Julia Shaw (Eds). 2018. Archaeology of Medicine and Healthcare. Special volume of World Archaeology 50 (3)

This volume calls for an archaeology of medicine and healthcare that moves beyond the study of discrete practices within specific settings to an evaluation of religio-medical worldviews and health beliefs in ancient times. This approach offers ways of mitigating and contextualizing modern global health challenges, with potential contributions to a wide range of emergent fields including community and public health, environmental and planetary health, genetic and epigenetic medicine, 'exposome' studies and ecological public health.

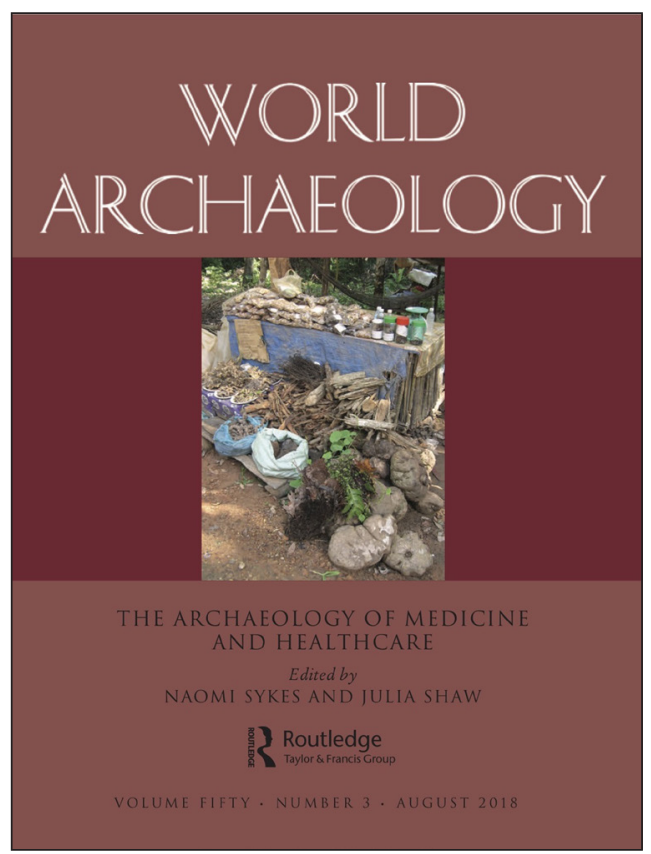

